\title{
Adição de insulina ao meio crioprotetor seminal de garanhões Mangalarga Marchador $^{1}$
}

\section{Bruno Fagundes ${ }^{2}$, Maurício Fraga van Tilburg ${ }^{2}$, José Frederico Straggiotti Silva ${ }^{2}$, Aldo Shimoya ${ }^{3}$, Marcus Antonio Pessanha Barreto², Vinicius Motta Ferreira ${ }^{2}$}

\footnotetext{
1 Projeto financiado pela Universidade Estadual do Norte Fluminense (UENF), Campos dos Goytacazes, RJ.

2 Universidade Estadual do Norte Fluminense - Laboratório de Reprodução e Melhoramento Genético Animal.

${ }^{3}$ Universidade Salgado de Oliveira - UNIVERSO Campos, RJ.
}

RESUMO - Objetivou-se verificar o efeito da adição de insulina $(0,1 ; 1$ ou $10 \mathrm{UI} / \mathrm{mL})$ ao diluente de congelamento convencional por meio de análise computadorizada das características de motilidade espermática (CASA), funcionalidade da membrana plasmática, por meio de choque hiposmótico, e integridade de membrana acrossomal, avaliada pelo teste FITC/PSA. Não houve efeito significativo da adição de 0,1 e $1 \mathrm{UI} / \mathrm{mL}$ de insulina na análise imediata após o descongelamento sobre os parâmetros de motilidade e cinemática espermática, porém o nível de $10 \mathrm{UI} / \mathrm{mL}$ de insulina promoveu redução desses parâmetros.

Palavras-chave: congelamento, equino, espermatozoide, membrana plasmática

\section{Adding insulin to frozen seminal extender from Mangalarga Marchador stallions}

\begin{abstract}
Success rates in equine sperm cryopreservation are lower than in other domestic species. The objective of this study was to verify the effect of adding $0.1 \mathrm{IU} / \mathrm{mL}, 1 \mathrm{IU} / \mathrm{mL}$ and $10 \mathrm{IU} / \mathrm{mL}$ insulin to conventional frozen extender using computerized analysis of sperm motility (CASA), plasma membrane functionality by hypo-osmotic shock and acrossomal membrane integrity through the FITC/PSA assay. No difference was observed in treatment with 0.1 and $1 \mathrm{IU} / \mathrm{mL}$ after thawing in the analysis of motility and kinematic sperm parameters. However, when $10 \mathrm{IU} / \mathrm{mL}$ insulin was used there was a reduction in these parameters.
\end{abstract}

Key Words: equine, freezing, plasmatic membrane, sperm

\section{Introdução}

Existe uma grande diferença na congelabilidade do sêmen entre garanhões e até mesmo entre ejaculados de um mesmo garanhão (Pickett \& Amann, 1993). Essa diferença também ocorre entre raças e a grande maioria dos garanhões Mangalarga Marchador é classificada como maus congeladores quando se utiliza apenas o glicerol como crioprotetor (Gomes et al., 2002). Alvarenga et al. (1996) observaram que a congelabilidade do sêmen de garanhões Mangalarga Marchador foi pior que a do sêmen de garanhões de salto e da raça Quarto de Milha.

A insulina é um hormônio anabólico que promove a captação de glicose e aminoácidos, a síntese de proteínas e lipídeos e o aumento das funções intracelulares e da membrana plasmática (Abdelmonein et al., 1998). Esse hormônio polipeptídico é essencial para o metabolismo normal e a regulação do crescimento mediante ligação com seu respectivo receptor transmembrana ou com receptores de IGF (fator de crescimento semelhante à insulina) na superfície da célula-alvo (Dupont et al., 2001). Hicks et al. (1972) observaram que a concentração de insulina no plasma seminal humano é quase três vezes maior que no sangue, o que sugere alguma função seminal. Kremer (1965), citado por Hicks et al. (1972), observou que, quando se utilizam glicose ou piruvato como substrato, a adição de insulina aumenta significativamente a motilidade de espermatozoides humanos, o que não ocorreu quando se utilizou frutose. Aitken (1994) relatou que hormônios, citosinas e fatores de crescimento presentes no plasma seminal afetam a motilidade espermática e a fertilização. Aquila et al. (2005) mostraram que espermatozoides humanos podem expressar e secretar insulina, o que sugere uma regulação autócrina do metabolismo da glicose, a qual é provida ao espermatozoide 
pelo plasma seminal e pelo fluido do trato reprodutivo da fêmea (Koch, 1980, citado por Aquila et al., 2005). Macpherson et al. (2002) observaram que a motilidade espermática total e a taxa de prenhez são maiores em garanhões com altas concentrações de IGF-I no plasma seminal. Van Tilburg et al. (2008) constataram melhora na integridade de acrossoma e na motilidade após o teste de termorresistência com a adição de insulina ao diluente de congelamento seminal ovino.

Este trabalho foi conduzido com a finalidade de verificar o efeito da insulina sobre a motilidade, a cinemática, a integridade de acrossoma e a funcionalidade de membranas espermáticas adicionadas ao meio crioprotetor seminal de garanhões da raça Mangalarga Marchador.

\section{Material e Métodos}

Foram utilizados cinco garanhões da raça Mangalarga Marchador provenientes do haras Lugavi em Campos dos Goytacazes - RJ. Inicialmente foram realizadas cinco coletas de sêmen de cada garanhão com intervalo de 2 dias, a fim de eliminar células espermáticas armazenadas por longo período. Em seguida, foram coletados três ejaculados de cada animal para realização deste trabalho.

O sêmen foi obtido utilizando-se uma vagina artificial modelo Hannover com a temperatura de $42{ }^{\circ} \mathrm{C}$ e uma égua em cio natural como manequim. A porção gelatinosa proveniente das vesículas seminais foi removida ao ficar retida no filtro de coleta.

A concentração espermática foi determinada com auxílio de uma câmara de Newbauer utilizando-se uma amostra do sêmen diluída na proporção de 1:200 de solução formol citrato preparada com 2,94 g de citrato de sódio em $100 \mathrm{~mL}$ de água destilada, removendo-se $4 \mathrm{~mL}$ desta solução e adicionando $4 \mathrm{~mL}$ de formaldeído (Merck ${ }^{\circledR}$ ).

O sêmen foi diluído em meio de resfriamento contendo $10 \mathrm{~g}$ de leite desnatado Molico ${ }^{\circledR}\left(\right.$ Nestle $\left.^{\circledR}\right)$ e $0,4 \mathrm{~g}$ de AGROVET $^{\circledR}$ (Novartis $^{\circledR}$ ) diluídos em $100 \mathrm{~mL}$ de água destilada q.s.p. na proporção de uma parte de sêmen para duas de diluente e em seguida foi centrifugado a $600 \mathrm{~g}$, durante 10 minutos, à temperatura ambiente. Cerca de $10 \mathrm{a}$ $20 \%$ do diluente de resfriamento com o plasma seminal foi preservado para ressuspensão com o diluente de congelamento proposto por Vidament et al. (2002) com modificações, contendo $50 \mathrm{~mL}$ de lactose $11 \% ; 25 \mathrm{~mL}$ de glicose-EDTA (12 $\mathrm{g}$ de glicose; $0,240 \mathrm{~g}$ de carbonato de sódio; 0,740 g de EDTA; 0,750 $\mathrm{g}$ de Citrato de sódio dihidratado; 0,8 g de AGROVET ${ }^{\circledR}$ (Novartis ${ }^{\circledR}$ ); $200 \mathrm{~mL}$ de água destilada q.s.p); $20 \mathrm{~mL}$ de gema de ovo; $3 \mathrm{~mL}$ de glicerol; $2 \mathrm{~mL}$ de dimetilformamida; $0,5 \mathrm{~mL}$ de Equex ${ }^{\circledR}$ Farmacia, Orvus et paste. Todos os demais reagentes descritos acima foram obtidos pela empresa VETEC.

Avaliou-se a adição de insulina ao diluente de congelamento ( $\operatorname{Iolin}^{\circledR}$ mista bovina e suína altamente purificada com concentração de $100 \mathrm{UI} / \mathrm{mL}$ ) da seguinte maneira: controle, $0,1 \mathrm{UI} / \mathrm{mL}, 1 \mathrm{UI} / \mathrm{mL}$ e $10 \mathrm{UI} / \mathrm{mL}$. Os parâmetros de motilidade e cinemática espermática foram avaliados utilizando-se o programa Ceros, versão 10.8, da Hamilton Thorn Research (HTM-CEROS), de funcionalidade de membrana plasmática pelo teste hiposmótico (Dell'aqua Jr. et al., 2001) e de integridade de membrana acrossomal pelo teste FITC-PSA.

A ressuspensão do sedimento de espermatozoides foi feita acrescentando-se o diluente de congelamento de acordo com os tratamentos, de forma a se obter uma concentração de $100 \times 10^{6}$ células $/ \mathrm{mL}$. O envase do sêmen foi feito em palhetas de $0,5 \mathrm{~mL}$, que foram mantidas em repouso por 20 minutos a $4{ }^{\circ} \mathrm{C}$ e em seguida, colocadas a 4 $\mathrm{cm}$ acima do nível do nitrogênio líquido durante 10 minutos e imersas neste criogênio para armazenamento.

A integridade funcional da membrana espermática foi avaliada por choque hiposmótico utilizando-se a técnica desenvolvida por Dell'Aqua Jr. et al. (2001) modificada. Em um tubo foram adicionados $190 \mathrm{~mL}$ de água bidestilada a $38{ }^{\circ} \mathrm{C}$ e $10 \mu \mathrm{L}$ do sêmen descongelado. A amostra foi incubada por 5 minutos em banho-maria a $38^{\circ} \mathrm{C}$ e em seguida foi colocada uma gota sobre a lâmina recobrindo-a com uma lamínula para análise em microscópio de contraste de fase com aumento de 400X. Foram contadas 200 células espermáticas, considerando funcionais aquelas com cauda enrolada e não-funcionais aquelas que permaneceram com a cauda esticada.

A integridade do acrossoma foi avaliada utilizando-se a fluoresceína isotiocianato conjugada com a Lectina Pisum sativum aglutinina (FITC-PSA), a qual se liga à glicoconjugados da membrana acrossomal externa ou à matriz acrossomal (Bedford et al., 2000) em associação ao iodeto de propídeo.

Após a análise da funcionalidade da membrana, motilidade e cinemática espermática, o sêmen descongelado foi centrifugado a $200 \mathrm{~g}$ por 2 minutos para remoção do diluente de congelamento e adição de PBS. Em seguida, foram preparados esfregaços das amostras, que foram secos à temperatura ambiente e mergulhados em metanol resfriado a $-10{ }^{\circ} \mathrm{C}$ no congelador por 30 segundos e novamente secos a temperatura ambiente. Foram colocados sobre cada lâmina $60 \mu \mathrm{L}$ de FITC-PSA sob proteção de luminosidade. Em seguida, as lâminas foram cobertas com 
um pedaço de transparência para retroprojeção e incubadas por 20 minutos. Cada lâmina foi adicionada de iodeto de propídio $(60 \mu \mathrm{L})$ e novamente coberta com um pedaço de transparência para retroprojeção e incubada por 10 minutos. As lâminas foram lavadas com PBS e cobertas com lamínula para observação em microscópio com ultra-violeta (UV) com aumento de 100X. Foram contadas 200 células por lâmina, classificadas como acrossoma íntegro (verde uniforme), parcialmente reagido (balloon ou danificado) e reagido (vermelho). O comprimento de onda utilizado na observação foi de $540 \mathrm{~nm}$ e todos os reagentes utilizados foram obtidos pela Sigma-Aldrich.

Os parâmetros de motilidade e cinemática espermática foram determinados por avaliação computadorizada utilizando-se o programa Ceros, versão 10.8, da Hamilton Thorne Research (HTM-CEROS, 1999). Uma câmara de contagem de $20 \mu \mathrm{L}$ (Hamilton Thorne Research) préaquecida pela placa de platina aquecedora $\left( \pm 37^{\circ} \mathrm{C}\right)$ foi utilizada para observação da amostra seminal por microscópio ótico com aumento de 100 vezes acoplado ao computador. A intensidade da fonte de luz foi ajustada para que as imagens dos espermatozoides fossem capturadas e digitalizadas para análise pelo programa.

Foram escolhidos quatro campos que apresentavam melhor motilidade aparente na amostra para análise e a média desses valores foi anotada e salva pelo programa para análise estatística.

Os dados obtidos foram submetidos à análise de variância e os tratamentos comparados pelo teste F. As médias dos tratamentos foram comparadas pelo teste de Tukey a $5 \%$ de probabilidade e as análises estatísticas foram realizadas utilizando-se o programa computacional Genes (Cruz, 2006) para determinação do efeito dos níveis de insulina dos garanhões e das coletas de sêmen.

\section{Resultados e Discussão}

A adição de insulina $(0,1$ e $1 \mathrm{UI} / \mathrm{mL})$ ao diluente de congelamento não promoveu diferença significativa nas análises de motilidade espermática, mas a adição de $10 \mathrm{UI} / \mathrm{mL}$ diminuiu a motilidade total e motilidade progressiva (Tabela 1 ).

A principal fonte de energia para o espermatozoide realizar diferentes funções relacionadas à motilidade, capacitação, penetração da zona pelúcida e fusão de membranas entre espermatozoide e ovócito é pela glicose (Travis et al., 2001). Entretanto, esse açúcar não penetra imediatamente nas membranas celulares, com exceção de poucos tecidos, como cérebro, fígado, leucócitos e hemácias, e a presença de insulina é essencial para movimentação da glicose pela membrana plasmática, induzindo o aumento do número de proteínas transportadoras específicas (Cunningham, 1997).

A adição da insulina ao meio de congelamento não melhorou a motilidade espermática na análise imediatamente após o descongelamento. Provavelmente isso ocorreu pelo curto tempo para penetração da glicose nas membranas espermáticas. Van Tilburg et al. (2008) verificaram que a adição de insulina melhorou os parâmetros de linearidade e retidão na análise após três horas do descongelamento, porém o efeito na análise imediata após o descongelamento também não melhorou os valores de motilidade. Uma provável razão para o efeito negativo da adição de $10 \mathrm{UI} / \mathrm{mL}$ de insulina sobre a motilidade total e progressiva é que o volume utilizado corresponde a pouco menos que $10 \%$ do volume do diluente utilizado, desse modo, pode não ter ocorrido interação adequada entre os crioprotetores desse meio com as células espermáticas.

A adição de 0,$1 ; 1$ e $10 \mathrm{UI} / \mathrm{mL}$ de insulina ao diluente de congelamento não teve efeito sobre a velocidade da cinemática espermática, mas a adição de $10 \mathrm{UI} / \mathrm{mL}$ de insulina diminuiu a amplitude lateral de cabeça em relação aos grupos controle e $0,1 \mathrm{UI} / \mathrm{mL}$ de insulina e aumentou a frequência de batimento flagelar em comparação à ausência de insulina (Tabela 2).

Correlações positivas altamente significativas entre motilidade progressiva e os parâmetros de velocidade indicam que o espermatozoide com trajeto linear progressivo e reto percorre uma distância maior em menor espaço de

Tabela 1 - Motilidade espermática imediatamente após o descongelamento do sêmen de garanhões Mangalarga Marchador criopreservado em meio contendo insulina

\begin{tabular}{ccccc}
\hline [Insulina] UI/mL & Motilidade total $(\%)$ & Motilidade progressiva (\%) & Retidão (\%) & Linearidade $(\%)$ \\
\hline 0 (Controle) & $31,6 \pm 18,0 \mathrm{a}$ & $19,8 \pm 12,0 \mathrm{a}$ & $78,3 \pm 3,6 \mathrm{a}$ & $45,2 \pm 3,7 \mathrm{a}$ \\
0,1 & $32,5 \pm 17,9 \mathrm{a}$ & $20,8 \pm 12,3 \mathrm{a}$ & $79,3 \pm 3,2 \mathrm{a}$ & $46,7 \pm 4,4 \mathrm{a}$ \\
1 & $31,6 \pm 18,5 \mathrm{a}$ & $20,8 \pm 13,3 \mathrm{a}$ & $78,9 \pm 4,0 \mathrm{a}$ & $46,5 \pm 4,3 \mathrm{a}$ \\
10 & $24,5 \pm 15,9 \mathrm{~b}$ & $15,7 \pm 10,5 \mathrm{~b}$ & $80,0 \pm 6,0 \mathrm{a}$ & $45,7 \pm 5,3 \mathrm{a}$ \\
Média geral & 30,0 & 19,3 & 79,1 & 46,0 \\
\hline
\end{tabular}

Médias seguidas pela mesma letra nas colunas não diferem entre si pelo teste de Tukey a $5 \%$ de probabilidade. 
Tabela 2 - Cinemática espermática no sêmen de garanhões Mangalarga Marchador criopreservado em meio com insulina

\begin{tabular}{lccrcr}
\hline & \multicolumn{3}{c}{ Insulina } & \multicolumn{2}{c}{ Média geral } \\
\cline { 2 - 5 } & $0 \mathrm{UI} / \mathrm{mL}$ (controle) & $0,1 \mathrm{UI} / \mathrm{mL}$ & $1 \mathrm{UI} / \mathrm{mL}$ & $10 \mathrm{UI} / \mathrm{mL}$ \\
\hline Velocidade média do percurso (ìm/s) & $55,9 \pm 11,1 \mathrm{a}$ & $55,8 \pm 11,9 \mathrm{a}$ & $55,0 \pm 11,5 \mathrm{a}$ & $52,0 \pm 12,3 \mathrm{a}$ & 54,7 \\
Velocidade linear (im/s) & $44,3 \pm 9,4 \mathrm{a}$ & $45,0 \pm 10,5 \mathrm{a}$ & $43,7 \pm 10,0 \mathrm{a}$ & $42,2 \pm 11,0 \mathrm{a}$ & 43,8 \\
Velocidade curvilínea (ìm/s) & $92,0 \pm 27,5 \mathrm{a}$ & $96,9 \pm 18,9 \mathrm{a}$ & $95,9 \pm 20,3 \mathrm{a}$ & $92,4 \pm 19,7 \mathrm{a}$ & 94,3 \\
Amplitude lateral de cabeça (ìm) & $5,2 \pm 0,6 \mathrm{a}$ & $5,1 \pm 0,7 \mathrm{a}$ & $5,0 \pm 0,9 \mathrm{ab}$ & $4,8 \pm 1,0 \mathrm{~b}$ & 5,0 \\
Frequência de batimento flagelar (Hz) & $22,3 \pm 6,4 \mathrm{~b}$ & $23,2 \pm 6,7 \mathrm{ab}$ & $23,3 \pm 7,9 \mathrm{ab}$ & $25,4 \pm 7,0 \mathrm{a}$ & 23,6 \\
\hline
\end{tabular}

Médias seguidas pela mesma letra nas colunas não diferem entre si pelo teste de Tukey a 5\% de probabilidade.

tempo. A velocidade média do percurso (VAP) e a velocidade linear (VSL) também têm forte correlação positiva com a fertilidade e podem ser utilizadas para estimar a fertilidade de amostras seminais (Kathiravan et al., 2008).

Com o aumento da concentração de insulina, houve queda na amplitude lateral da cabeça do espermatozoide, aumentando a frequência de batimento flagelar. Desse modo, os espermatozoides tiveram melhor aproveitamento energético durante seu trajeto. Mortimer (1997) reportou que o aumento na viscosidade do diluente diminui a amplitude da onda flagelar. Geralmente, amplitude lateral de cabeça elevada não é desejável porque afeta a progressão celular, desse modo, valores mais elevados de ALH denotam menor qualidade da amostra seminal (Arruda et al., 2003).

Rathi et al. (2001) postularam que a amplitude lateral da cabeça e a velocidade curvilínea aumentam em espermatozoides equinos hiperativados em meio contendo agentes capacitantes, como bicarbonato e $\mathrm{Ca}^{2+}$ ionóforo. Esses autores concluíram que espermatozoides equinos hiperativados apresentam VCL $\geq 180 \mu \mathrm{m} / \mathrm{s}$ e $\mathrm{ALH} \geq 12 \mu \mathrm{m}$, o que não ocorreu neste experimento.

A adição de 0,$1 ; 1$ e $10 \mathrm{UI} / \mathrm{mL}$ de insulina ao diluente de congelamento também não teve efeito sobre as análises de funcionalidade de membrana plasmática e integridade de membrana acrossomal (Tabela 3 ).

O processo de resfriamento altera a fluidez da bicamada fosfolipídica, fazendo com que os fosfolipídeos semelhantes agrupem-se e excluam proteínas da membrana, diminuindo sua mobilidade e, assim, a funcionalidade da membrana (Jasko, 1994). A adição de insulina não melhorou essa perda na funcionalidade de membrana nem a integridade acrossomal, provavelmente em decorrência de sua ação no metabolismo espermático, mas não evidenciado efeito crioprotetor desse hormônio.

A capacitação é caracterizada por um padrão de movimento pela maioria dos espermatozoides no ato da fertilização e esses espermatozoides hiperativos tendem a movimentar-se vigorosamente em círculos (Ho \& Suarez, 2001). Aquila et al. (2005) sugeriram um possível envolvimento da insulina na indução da capacitação de espermatozoides humanos. Entretanto, neste experimento os valores de velocidade curvilínea foram inferiores a $180 \mu \mathrm{m} / \mathrm{s}$ e a amplitude lateral de cabeça foi menor que $12,0 \mu \mathrm{m}$ para todas as concentrações de insulina utilizadas, valores compatíveis com espermatozoides não-capacitados (Rathi et al., 2001). Além disso, a integridade acrossomal também não foi afetada pela adição de insulina (Tabela 3 ).

A concentração de glicose no meio é o principal fator de liberação de insulina. A glicose aumenta a quantidade de ATP pela cadeia respiratória nas células $\beta$ das ilhotas pancreáticas e os níveis de ATP controlam o fechamento dos canais de $\mathrm{K}^{+}$e a despolarização da membrana plasmática. A despolarização faz com que os canais de $\mathrm{Ca}^{2+}$ se abram e esse íon flua para dentro da célula provocando a liberação de insulina já sintetizada (Jeffrey \& Alan, 2000). Esse mecanismo é semelhante nos eventos que antecedem a fertilização, que envolvem a capacitação e a reação acrossômica, apesar de cerca de $90 \%$ da produção de ATP no espermatozoide maduro ser obtida por glicólise (Mukay \& Okuno, 2004). $\mathrm{OCa}^{2+}$ extracelular é requerido tanto na capacitação espermática quanto na indução da reação acrossômica (Kaul etal., 1997) e o início da reação acrossômica depende de um aumento intracelular massivo dos níveis de $\mathrm{Ca}^{2+}$ na célula espermática (Bailey \& Bayard, 1994).

Colenbrander et al. (2000) mostraram que a glicose no diluente favorece a reação acrossômica em espermatozoides de cão e de hamster. Aquila et al. (2005) demonstraram que a estimulação da secreção de insulina pela célula espermática

Tabela 3 - Médias de membranas funcionais (hiposmótico) e acrossomas íntegros (PSA) no sêmen de garanhões Mangalarga Marchador imediatamente após o descongelamento

\begin{tabular}{|c|c|c|}
\hline Insulina & \%Hiposmótico & $\%$ PSA \\
\hline $0 \mathrm{UI} / \mathrm{mL}$ (controle) & $30,1 \pm 11,2 \mathrm{a}$ & $68,2 \pm 15,5 \mathrm{a}$ \\
\hline $0,1 \mathrm{UI} / \mathrm{mL}$ & $31,4 \pm 12,9 \mathrm{a}$ & $71,7 \pm 15,2 \mathrm{a}$ \\
\hline $1 \mathrm{UI} / \mathrm{mL}$ & $30,9 \pm 13,9 a$ & $71,6 \pm 17,1 \mathrm{a}$ \\
\hline $10 \mathrm{UI} / \mathrm{mL}$ & $32,2 \pm 13,8 \mathrm{a}$ & $73,3 \pm 14,6 a$ \\
\hline Média geral & 31,2 & 71,2 \\
\hline
\end{tabular}


é dose-dependente de glicose, assim como as células $\beta$ do pâncreas. É possível que, na ausência de insulina no plasma seminal ou no diluente, o espermatozoide seja estimulado a liberar sua reserva de insulina para manter seu metabolismo. Esse processo acarreta a entrada de $\mathrm{Ca}^{2+}$ e ativa os mecanismos da reação acrossomal. Com a adição de insulina nos meios crioprotetores, os espermatozoides não necessitariam liberar suas reservas de insulina para captar a glicose do meio e não acarretariam a entrada de $\mathrm{Ca}^{2+}$ nos mesmos nem a ativação dos mecanismos da reação acrossomal.

A capacitação tem sido correlacionada a alterações no metabolismo celular, na concentração intracelular de íons, na fluidez da membrana plasmática, no pH intracelular e na concentração intracelular de AMPc (Visconti et al., 1998). Entretanto, ainda não se sabe ao certo os mecanismos de ação da insulina no espermatozoide.

Mesmo não atuando diretamente na crioproteção, o fato de não ter influenciado na capacitação, a redução na amplitude lateral de cabeça e o aumento da frequência de batimento flagelar sugerem que a adição de insulina pode ser utilizada para atuação no metabolismo espermático e na manutenção da qualidade da amostra seminal de garanhões da raça Mangalarga Marchador. Entretanto, existe a necessidade de maiores estudos para determinar em qual mecanismo metabólico a insulina atua no espermatozoide e qual sua correlação com a fertilidade.

\section{Conclusões}

A adição de $0,1 \mathrm{UI} / \mathrm{mL}$ e $1 \mathrm{UI} / \mathrm{mL}$ de insulina ao meio de congelamento de sêmen equino não teve efeito citotóxico às células espermáticas após o descongelamento.

\section{Referências}

ABDELMONEIN, I.Y.; BETH, R.; SABA, K. et al. The effects of antifreeze peptide III (AFP) and insulin transferrin selenium (ITS) on cryopreservation of chimpanzee (Pan troglodytes) spermatozoa. Journal of Andrology, v.19, p.207, 1998.

AITKEN, R.J. Pathophysiology of human spermatozoa. Current Opinion in Obstetrics and Gynecology, v.6, p.128-135, 1994.

ALVARENGA, M.A.; PAPA, F.O.; BURATINI JUNIOR, J. The effect of breeds spermatic parameters over equine semen freezability. In: SYMPOSIUM OF STALLION SEMEN, 1996, Amersfoort. Proceedings.... Amersfoort, 1996. p.82.

AQUILA, S.; GENTÍLE, M.; MÍDDEA, E. et al. Autocrine regulation of insulin secretion in human ejaculated spermatozoa. Endocrinology, v.146, n.2, p.552-557, 2005.

ARRUDA, R.P.; BALL, B.A.; GRAVANCE, C.G. et al. Evaluation of effects of extenders and cryoprotectants on equine spermatozoa using computer-assisted sperm analyses (CASA) and flow cytometry. Acta Scientiae Veterinariae, v.31, p.228-229, 2003.
BAILEY, J.L.; BAYARD, T.S. Calcium influx into mouse spermatozoa activated by solubilized mouse zona pellucida, monitored with calcium fluorescent indicator, Fluo-3. Inhibition of the influx by three inhibitors of the zona pellucida induced acrosome reaction: tyrphostin A48, pertussis toxin and 3-quinuclidinyl enzilate. Molecular Reproduction and Development, v.39, p.297-308, 1994.

BEDFORD S.J.; VARNER D.D.; MEYERS S.A. Effects of cryopreservation on the acrossomal status of stallion spermatozoa. Journal of Reproduction and Fertility, v.56, p.133-140, 2000

COLENBRANDER, B.; SIRIVAIDYAPONG, F.P.C.; CHENG, F.P. et al Effect of sperm diluents on the acrosome reaction in canine sperm. Theriogenology, v.53, p.789-802, 2000.

CRUZ, C.D. Programa GENES: estatística experimental e matrizes. Viçosa, MG: Editora UFV, 2006. 285p.

CUNNINGHAM, D.V.M. Tratado de fisiologia veterinária, 2.ed. Rio de Janeiro: Guanabara Koogan, 1997. 528p.

DELL'AQUA JR., J.A.; PAPA, F.O.; ALVARENGA, M.A. et al. Effect of packing systems and thawing temperature on spermatic parameters and fertility rate of frozen equine semen. Revista Brasileira de Reprodução Animal, v.25, p.458-460, 2001

DUPONT, J.; KHAN, J.; QU, B.H. et al. Insulin and IGF-I induce different patterns of gene expression in mouse fibroblast NIH-3T3 cells: identification by cDNA microarray analysis. Endocrinology, v.142, n.11, p.4968-4975, 2001.

GOMES, G.M.; JACOB, J.C.F.; MEDEIROS A.S.L. et al. Improvement of stallion spermatozoa with alternative cryoprotectants for the Mangalarga Marchador breed. Theriogenology, v.58, p.277-279, 2002.

HICKS, J.J.; ROJAS, L.; ROSADO, A. Insulin regulation of spermatozoa metabolism. In: INTERNATIONAL CONGRESS OF ENDOCRINOLOGY, 4., 1972, Washington, D.C. Anais... Washington, D.C., 1972. p.833-839.

JASKO, D.J. Procedures for cooling and freezing of equine semen. ARS Veterinary, v.10, p.180-190, 1994.

JEFFLEY, E.P.; ALAN, R.S. Signaling pathways in insulin action: molecular targets of insulin resistance. The Journal of Clinical Investigation, v.106, p.165-169, 2000.

HO, H.C.; SUAREZ, S.S. Hyperactivation of mammalian spermatozoa: function and regulation. Reproduction, v.122, p.519-526, 2001.

KATHiRAVAN, P.; KAlathaRAN, J.; EDWIN, M.J. et al. Computer automated motion analysis of crossbred bull spermatozoa and its relationship with in vitro fertility in zonafree hamster oocytes. Animal Reproduction Science, v.104, p.9-17, 2008.

KAUL, G.; SINGH, S.; GANDHI, K.K. et al. Calcium requirement and time course of capacitation of goat spermatozoa assessed by chlortetracycline assay. Andrologia, v.29, n.5, p.243-251, 1997.

MACPHERSON, M.L.; SIMMEN, R.C.M.; SIMMEN, F.A. et al. Insulin-like growth factor-I and insulin-like growth factor binding protein-2 and -5 equine seminal plasma: Association with sperm characteristics and fertility. Biology of Reproduction, v.67, p.648-654, 2002 .

MORTIMER, S.T. A critical review of the physiological importance and analysis of sperm movement in mammals. Human Reproduction Update, v.3, p.403-439, 1997.

MUKAI, C.; OKUNO, M. Glycolisis plays a major role for adenosine triphosphate supplementation in mouse sperm flagellar movement. Biology of Reproduction, v.71, p.540-547, 2004.

PICKETT, B.W.; AMANN, R.P. Cryopreservation of Semen. In: MCKINNON, A.O.; VOS, J.L. (Eds.) Equine reproduction. Philadelphia: Lea \& Febiger, 1993. p.769-789.

RATHI, R.; COLENBRANDER, B.; BEVERS, M.M. et al. Evaluation of in vitro capacitation of stallion spermatozoa. Biology of Reproduction, v.65, p.462-470, 2001. 
TRAVIS, A.J.; JORGEZ, C.J.; MERDIUSHEV, T. et al. Functional relationships between capacitation-dependent cell signaling and compartmentalized metabolic pathways in murine spermatozoa. Journal Biology Chemical, v.276, p.7630-7636, 2001.

VAN TILBURG, M.F.; SILVA, J.F.S.; DIAS, A.J.B. et. al. Influência da insulina no congelamento e resfriamento do sêmen ovino. Ciência Animal Brasileira, v.9, n.3, p.731-739, 2008.
VIDAMENT, M.; DAIRE, C.; YVON, J.M. et al. Motility and fertility of stallion semen frozen with glycerol and/or dimethyl formamide. Theriogenology, v.58, p.249-251, 2002 .

VISCONTI, P.E.; GALANTINO-HOMER, H.; MOORE, G.D. et al. The molecular basis of sperm capacitation. Journal of Andrology, v.19, p.242-248, 1998. 